\title{
Boletina dispectoides sp.n. and six other species of fungus gnats (Diptera: Mycetophilidae) new to Finland
}

\author{
Jevgeni Jakovlev \& Jouni Penttinen
}

Jakovlev, J. \& Penttinen, J. 2007: Boletina dispectoides sp.n. and six other species of fungus gnats (Diptera: Mycetophilidae) new to Finland. - Entomol. Fennica 18: 211-217.

Boletina dispectoides Jakovlev \& Penttinen sp.n., a new species of the Boletina nitida group is described. In addition, six other species of fungus gnats are reported from Finland for the first time. Manota unifurcata Lundström, 1913 was reared from dead wood. Exechia bicincta Staeger, 1840, Mycetophila forcipata Lundström, 1913, M. sumavica (Lastovka, 1963), Trichonta tristis (Strobl, 1898) and Sciophila plurisetosa Edwards, 1921 were caught by pit-fall and Malaise traps in southern and central Finland. Detailed information on Finnish records as well as data on the general distribution of the species and their larval microhabitats is given.

J. Jakovlev, Finnish Forest Research Institute (METLA), Vantaa Research Unit, P.O.Box18,FI-01301 Vantaa, Finland; jevgeni.jakovlev@metla.fi

J. Penttinen, Department of Bio- and Environmental Sciences, University of Jyväskylä, P.O Box 35, FI-40014, Jyväskylä, Finland. E-mail: jokrpent (a)cc.jyu.fi

Received 29 Nov 2006, accepted 1 March 2007

\section{Introduction}

Since the start of the Finnish PUTTE study program for poorly known and threatened species in 2003, altogether 112 species of fungus gnats (Diptera: Bolitophilidae, Diadocidiidae, Ditomyiidae, Keroplatidae, Mycetophilidae) have been reported as new to Finland (Jakovlev et al. 2006, Polevoi et al. 2006) increasing the known Finnish fauna to 699 species.

Further studies have yielded additional seven species of fungus gnats new to the fauna of Finland, including one species new for science. This species, Boletina dispectoides sp.n., belongs to the Boletina nitida group that was recently revised by Zaitzev et al. (2005) on the part of it's Palaearctic species. The $B$. nitida group including $B$.dispectoides incorporates ten species, of which eight present in Finland. The species of the $B$. nitida group can easily be distinguished from the rest of genus Boletina by their hairy laterotergite in combination with bare $\mathrm{Sc}$ and the presence of Sc2 (Zaitzev et al. 2005). In this article a description of the new species is given as well as faunistic and ecological data on the other species new to Finland.

\section{Material and methods}

The species new to Finland were found studying the fungus-gnat material collected in 2004-2005 by Malaise and pit-fall trapping, sweep-netting and rearing from larvae in southern and central Finland, within the biological provinces of Varsinais-Suomi $(A b)$, Uusimaa $(N)$, Etelä-Häme $(T a)$ 

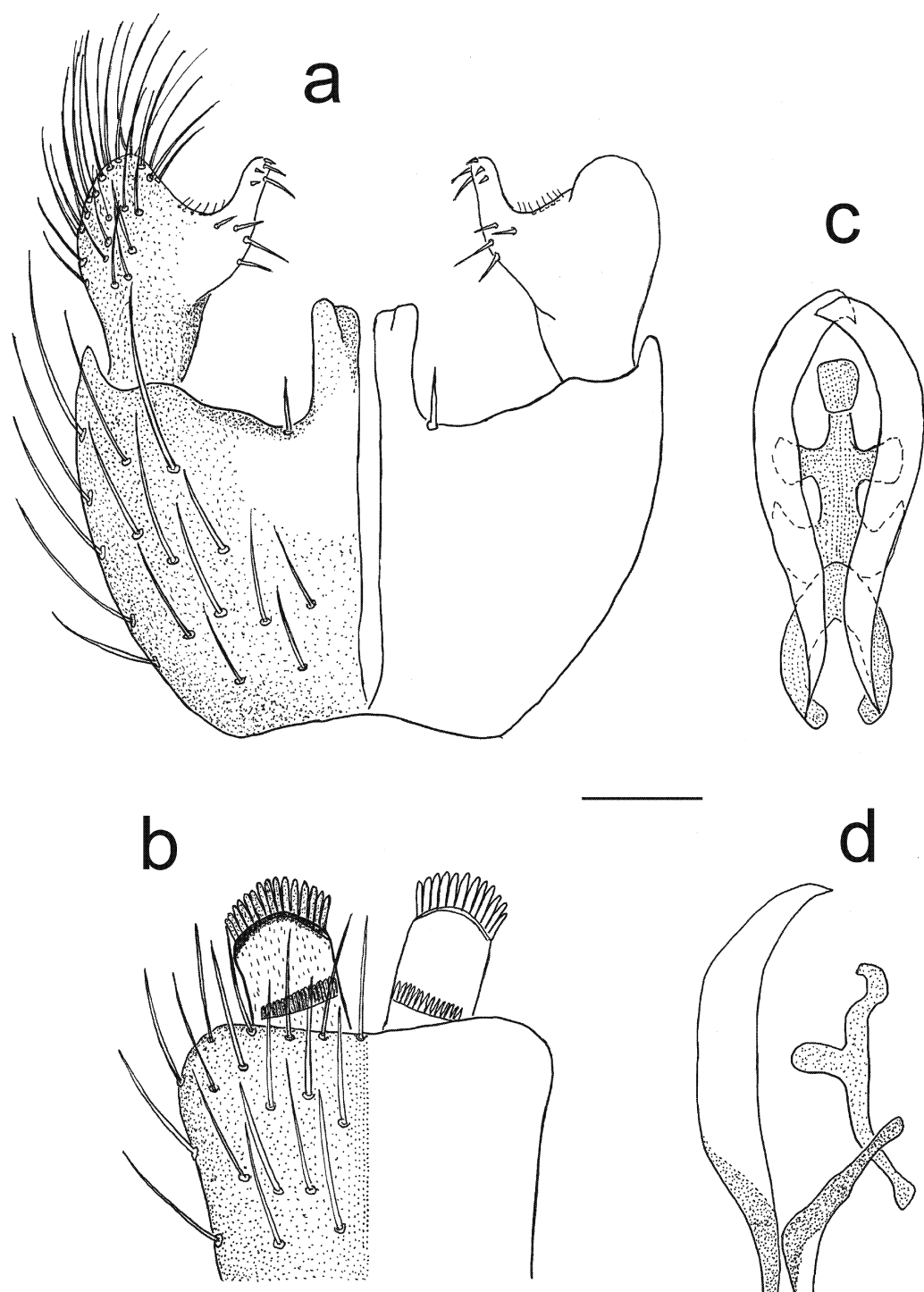

and Pohjois-Häme $(T b)$. Detailed information on the collecting localities for each species is given separately.

As pit-fall traps we used plastic mugs (volume $2 \mathrm{dl}$, diameter of $6.5 \mathrm{~cm}$ ) buried to the upper edges of the mugs in the debris at the bottom of hollow tree trunks and casserole dishes made of aluminum foil (volume $5 \mathrm{dl}$, size $13 \times 10.5 \mathrm{~cm}$ ) attached with pins to the barkless trunks.

Malaise and pit-fall traps were operated from mid-May to mid-October and emptied 4-6 times during this interval. $70 \%$ alcohol or a $50 \%$ ethyl- ene glycol with some detergent was used as a preserving fluid in the traps. For rearing adult fungus gnats from larvae living in decaying wood we used emergence traps described in detail by Jakovlev (2005).

Additional records of species new to Finland were obtained by reviewing selected parts of the collections of the Zoological Museum, Finnish Museum of Natural History (MZH).

The structure of the records presented below is: number of males, number of females, code for biogeographical province (Heikinheimo \& Raati- 


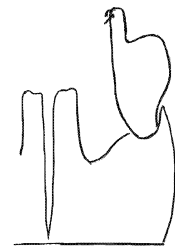

a
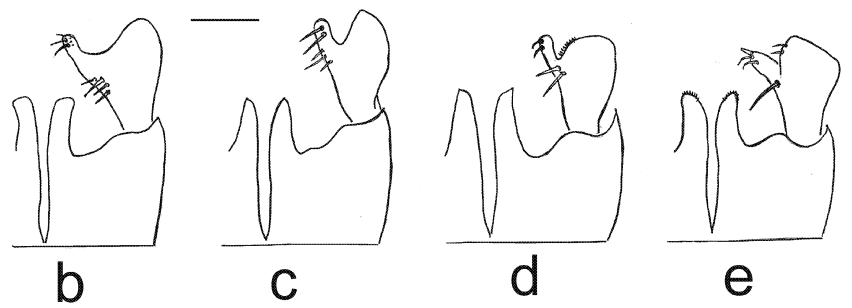

Fig. 2. Boletina nitida group, male genitalia in ventral view. - a. B. bidenticulata Sasakawa \& Kimura, 1974. - b. B. dispectoides Jakovlev \& Penttinen, sp. n. - c. B. dispecta Dziedzicki, 1885. - d. B. gusakovae Zaitzev, 1994. - e. B. rejecta Edwards, 1941. Scale bar $0.1 \mathrm{~mm}$.

kainen 1971), municipality, location, coordinates (according the Finnish national grid coordinate system), date and collector. The morphological terminology used follows that of Søli (1977).

The specimens are dry-pinned. Genitalia were treated in a standard way (heating in a solution of $\mathrm{KOH}$, neutralization in acetic acid and washing in distilled water) and preserved as glycerine preparations in small vials on the same pin as the rest of the body. The genitalia of the holotype of the new species are mounted in the Euparal slide on transparent insect mounting card on the same pin as the rest of the body.

The holotype, one of the paratypes of the newly described species, Boletina dispectoides sp.n., and pinned voucher specimens of all the species new to Finland are deposited in the collections of MZH.

\section{Description of a new species, Boletina dispectoides Jakovlev \& Penttinen sp. n. (Fig 1, a-d)}

Type material. Holotype $\widehat{\jmath}$, Finland, Tb: Keuruu, Häntämäki, 6907992:3382482, Malaise trap 10.IX.-16.X.2005, J. Penttinen leg. Paratypes. 2 $\hat{\delta} \hat{\partial}$, same data as holotype; $1 \hat{\delta}$, Finland, Ta: Lammi, Hattukivenmaa, Malaise trap 28.VIII.4.X.2004, J. Jakovlev leg.

The collecting locality in Häntämäki is an ordinary clear-cut forest stand. The collecting locality in Hattukivenmaa is a clear-cut with retention trees treated with prescribed burning.

Additional material. $1 \delta$, Russian Karelia, Kon, Kivach Nature Reserve, Malaise trap, 25.IX-1.X.1990, Jakovlev \& Polevoi leg. The collecting locality is a herb-rich aspen dominated forest.

Description. Male. Head dark brown, mouth parts brownish. Palpi brownish, fourth segment yellow with only the tip darkened. Clypeus dark brown. Antennae dark brown, sixth flagellomere two times as long as wide.

Thorax. Mesonotum shining dark brown, covered with dense yellowish hairs. Pleurae dark brown, laterotergite hairy.

Legs. Coxae and femora yellow, trochanters dark brown, tibiae and tarsi brownish. Leg ratios: $\mathrm{t} 1$ : bt1 $=1.4 ; \mathrm{t} 2$ : bt2 $=1.7$; 3 : bt3 $=1.8$.

Wings. Wing length $3.5 \mathrm{~mm}$. Wings hyaline, Sc bare, ending above (in some specimens very slightly before or beyond) base of Rs, Sc2 present, a little beyond the middle of Sc. C extending beyond the tip R $4+5$ to approximately $1 / 2$ of the distance between R4+5 and M1, stem of M-fork 1.2 times as long as rm. Halters yellow.

Abdomen. Uniformly brown.

Male genitalia as in Fig.1, dark brown. Sternal submedian appendages of gonocoxite moderately long, exceeding the bases of gonostyles, and relatively broad with parallel sides, widely rounded apically, almost truncated. Gonostyles with an elongated thumb-like process which bears three short spines and two strong bristles apically and four bristles (two longer and two shorter) at the base, near the middle of gonostylus. Tergite IX rectangular with distal margin slightly concave to almost straight. Cerci elongate with an apical comb of strong spines and one row of shorter spines near the base. Parameres relatively short, do not exceed the level of sternal submedian appendages, pointed to apices and slightly bent in the middle. 
Female. Unknown.

Larval biology. Unknown.

Etymology. The species' name indicates its resemblance to $B$. dispecta.

Diagnostic characters. There are now five closely related species of the Boletina nitidagroup characterized with a similar shape of gonostyles bearing a very typical elongated finger-like process (which is $3-4$ times as long as wide) armed with strong apical spines, and with moderately long sternal appendages of gonocoxites slightly exceeding the bases of gonostyles (Fig. 2, a-e). The other three species of Boletina nitida-group occurring in Europe (B.nitida Grzegorzek, 1885, B. falcata Polevoi \& Hedmark, 2004, and B. hedstroemi Polevoi \& Hedmark, 2004) have clearly different shape of gonostyles.

The new species, $B$. dispectoides, differs from B. dispecta Dziedzicki, 1885, B. gusakovae Zaitzev, 1994 and B. rejecta Edwards, 1941 in having sternal submedian appendages of gonocoxites widely rounded apically while the three other species have sternal submedian appendages of gonocoxites narrowing apically. According to the key to Palaearctic species of the Boletina nitida-group (Zaitzev et al. 2005, p.252) the new species, $B$. dispectoides, runs to the couplet 3: "ventral processes of gonocoxites widely rounded apically, almost rectangular" leading to B. bidenticulata Sasakawa \& Kimura, 1974 from which the new species differs primarily by the shape of gonostyles (Table 1).

The shape of gonostyles of $B$. dispectoides is very similar to that of $B$. dispecta, but in $B$. dispectoides the gonostyles are rounded apically (humpbacked) while in B. dispecta they are slightly pointed apically.
$B$. dispectoides can be distinquished from $B$. dispecta also by more dense hair cover on the mesonotum, by the slightly shorter flagellar segments ( 2 times as long as wide in $B$. dispectoides vs 2,5 times as long as wide in $B$. dispecta) and by the shorter stem of M-fork (1.2 times as long as $\mathrm{rm}$ in $B$. dispectoides vs 1.7 times as long as $\mathrm{rm}$ in B. dispecta).

\section{New species of Mycetophilidae to Finland}

\subsection{Subfamily Manotinae}

\section{Manota unifurcata Lundström, 1913}

Material examined. 1 o, Ta: Lammi, Lammi biological station, 67731:33946, reared from decaying wood of black alder (Alnus glutinosa) bearing fruiting bodies of Fomitopsis pinicola. Leg. 1.VII.2005, emergence 27.VII.2005, J. Jakovlev leg. The collecting site is an herb-rich forest on calcareous soil with a big proportion of deciduous trees and hazel (Corylus avellana).

Distribution data. A rare species belonging to the subfamily Manotinae distributed mainly in tropical areas (Hippa et al. 2004, Jaschhof \& Hippa 2005). In central and southern Europe $M$. unifurcata is known from several countries, viz. Britain, France, Denmark, Czech Republic, Poland, Hungary (described from there), Romania and Ukraine (Chandler 2005). In the Nordic region recorded only from Russian Karelia (Polevoi 2000) and the neighboring Vologda province of Northwest Russia (Zaitzev 2003).

Larval biology. There are only two former rearing records from larvae found in rotten beech

Table 1. Diagnostic characters of the closely related species of the Boletina nitida-group.

Species Gonostylus

Sternal appendages of gonocoxite

1. B. bidenticulata Sasakawa et Kimura

2. B. dispectoides sp. $\mathrm{n}$. Jakovlev et Penttinen

3. B. dispecta Dziedzicki

4. B. gusakovae Zaitzev

5. B. rejecta Edwards straight apically, fingerlike processus arises from the top of gonostyle narrowly rounded apically (humpbacked) slightly pointed apically widely rounded apically almost truncated apically widely rounded apically, almost truncated widely rounded apically, almost truncated narrowing apically narrowing apically narrowing apically 
wood bearing an unidentified myxomycete (Chandler 1978) and on the surface of very moist, rotten birch wood covered with a grayish coat of an unidentified fungus (Zaitzev 1990).

\subsection{Subfamily Mycetophilinae}

\subsubsection{Tribe Exechiini}

Exechia bicincta Staeger, 1840

Material examined. $2 \hat{\jmath}, N$ : Espoo, Träskända protected park area, 6682419: 3373127, pit-fall traps: a plastic mug inside a hollow lime tree (Tilia cordata), 22.VI.-12.VII. 2005, and an aluminium casserole dish attached on the barkless trunk of a maple tree (Acer platanoides), 13.VII.-3.VIII.2005, J.Mattila \& J. Siitonen leg. The collecting locality is an old protected mansion park in the city of Espoo with numerous old hollow deciduous trees, mainly lime trees, oaks and maples. Several red-listed saproxylic beetle species have been found within the park (Mattila \& Siitonen, pers. com.).

Distribution data. A holarctic species widespread in Central and Southern Europe, Near East (Chandler 2005) and Russian Far East (Zaitzev 2003). In the Nordic region found only in Denmark, Sweden and in the neighboring areas: Estonia, Latvia (Chandler 2005) and Russia: Leningrad district (Krivosheina et al. 1986).

Larval biology. Larvae live in soft fruiting bodies of a wide range of epigeal and woodgrowing fungi. There are rearing records from Pleurotus ostreatus, Hygrophoropsis aurantiaca, Tricholoma populinum, Collybia acervata, Mycena inclinata, M. galericulata, Tricholomopsis platyphylla in Hungary (Dely-Draskovitš 1974) and Czech Republic (Sedivy \& Ševčík 2003), Omphalotus olearius in Portugal (Ribeiro 1990), Gomphidius viscidus in Germany (Eisfelder 1955), Pluteus salicinus in the British Isles (Chandler 1993) and Russula virescens in Tatasrstan (Khalidov 1984).

\subsubsection{Tribe Mycetophilini}

Mycetophila forcipata Lundström, 1913

Material examined. $1 \hat{\delta}$, Ta: Lammi, Puukkohonka, 6791991:3395557 Malaise trap
28.VII-28.VIII.2004, J. Jakovlev leg. $1 \hat{\jmath}$, Tb: Laukaa, Vehmasmäki, 6927436:3435854, Malaise trap 15.-28.VII.2005, J. Penttinen leg. The collecting localities are Norway spruce (Picea abies) dominated, Myrtillus type forests, Puukkohonka as old-growth forest and Vehmasmäki, a mature managed forest.

Distribution data. Transpalaerctic species widely distributed in Europe but in the Nordic region recorded only from Sweden (Chandler 2005). According to the Catalogue of Palaearctic Diptera (Lastovka 1988) M. forcipata is also found in Finland, but was not mentioned in the Finnish Diptera check-list (Hackman 1980). We have not found the holotype material indicated by Lundström (1913, p.318) as: "1 ô, Laponia suecica, Muonio, 8/VII.1911. Leg. Frey. (Mus. Univ. Helsingfors)" in the collections of $\mathrm{MZH}$, but only two males of $M$. forcipata, each with the label "Ponoj. R.Frey" recorded by Lundström (1914) from Kola Peninsula (Laponia rossica), Russia.

Larval biology. All existing rearing records are restricted to wood-growing polypores: Piptoporus betulinus: 'larvae at base of tubes, pupa in soil' (Edwards 1925; Chandler 1978) and Polyporus squamosus (Madwar 1937). These records however could also concern the other species, Mycetophila pseudoforcipata Zaitzev 1998, that was described long after $M$. forcipata. Ševčík (2004) reported the true $M$. forcipata from Piptoporus betulinus.

Mycetophila sumavica (Lastovka, 1963)

Material examined. 1 oे, Tb: Rautalampi, Kalajanvuori, 6941603:3484673, Malaise trap, 3.V.-6.VI.2004, J. Penttinen leg. 1 đै, Tb: Toivakka, Huhtalampi, 6883884:3461804, Malaise trap 14.-28.V.2005, J. Penttinen leg. Both collecting localities are Norway spruce dominated, Myrtillus-type old-growth forests with a plenty of deciduous and coniferous coarse woody debris.

Distribution data. The species is widely distributed in Europe including the Nordic region. Data from Finland are given without finding localities by Chandler (2005).

Larval biology. Unknown.

Trichonta tristis (Strobl, 1898)

Material examined. $1 \hat{\jmath}, A b$ : Karkali Strict Nature Reserve, 6685084:3322111, Malaise trap 23.VIII.-4.X.2005, J. Jakovlev leg. The collect- 
ing locality is a herb-rich forest on calcareous soil with a big proportion of deciduous trees and hazel (Corylus avellana). 1 §, Ta: Lammi, Kotinen Strict Nature Reserve, 6794650:3396561, Malaise trap 10.IX.-3.X.2003, J. Jakovlev leg. The collecting locality is a Norway spruce dominated, Myrtillus-type old-growth forests with a plenty of deciduous and coniferous coarse woody debris. 1 ô, $N$ : Sipoo, Käsis-Solbacka, 6705233:3400733, Malaise trap 13.V-13.VI.2005, J. Jakovlev leg. The collecting locality is a young spruce-dominated, unmanaged forest. 1 $\hat{\delta}, T b$ : Äänekoski, Kylmähauta, 6935631:3432365, sweep net 16.VI.2005, J. Penttinen leg. The collecting locality is a lush, spring-water fed spruce mire forest in a natural state. 1 के, Ta: Lammi, Leipäsuonaho, 6789920:3395865, reared from a decaying spruce stump bearing resupinate fruiting bodies of the polypore Antrodia xantha. Leg. 28.VIII.2004, emergence 5.X.2004, J. Jakovlev leg. The collecting locality is a clear-cut with retention trees treated with prescribed burning.

Distribution data. Recorded only from Austria (described from there), Switzerland (Chandler 2005), Russia, Siberia (Krasnoyarsky region) and the Far East (Zaitzev 2003). The species is similar to the more common Trichonta vulcani Dziedzicki 1889 and could easily have been overlooked in many studies. Records of T. vulcani from Kivach Nature Reserve, Russian Karelia (Polevoi 2000) refer to T. tristis (A. Polevoi, pers. comm.).

Larval biology. There are no former rearing records.

\subsection{Subfamily Sciophilinae}

Sciophila plurisetosa Edwards, 1921

Material examined. 1 ô, $N$ : Tuusula, Ruotsinkylä, 6695638:3390934, Malaise trap 13.V13.VI.2005, J. Jakovlev leg. The collecting locality is a clear-cut forest stand.

Distribution data. A rare species with a Holarctic distribution. In Europe reported from Britain, Germany, Austria and Czech Republic (Chandler 2005). In the Nordic region recorded only from southern Sweden (Kurina et al. 2004).

Larval biology. Reared from Hydnum repandum in the British Isles (Chandler 1987) and
Hirneola auricula-judae in the Czech Republic (Ševčík 2005).

Acknowledgements. The material was collected in PUTTE research program, project "Finnish fungus gnats (Diptera, Mycetophilidae, etc.): faunistics, habitat requirements and threat status". The financial support from the Finnish Ministry of Environment is hereby acknowledged. Trapping was also partly funded by the Finnish Expert Group for Diptera and Societas pro Fauna et Flora Fennica. Juha Siitonen and Jaakko Mattila (METLA) are provided us with the material collected in Träskända park area. We are indebted to Alexei Polevoi (Petrozavodsk, Russia) and the anonymous referee for comments to the manuscript.

\section{References}

Chandler, P. J. 1978: Associations with plants. Fungi. In: Stubbs, A \& Chandler, P. I. (eds.), A Dipterist's Handbook. Amateur Entomologist 15:199-211. The Amateur Entomologist's Society, Middlesex. 255 pp.

Chandler, P. J. 1987: Notes on British fungus gnats of the smaller families and sub-families (Diptera, Mycetophiloidea). - Proc. Trans. Br. Entomol. Nat. Hist. Soc. 20: 105-118.

Chandler, P. J. 1993: New rearing records of fungus gnats (Diptera:Mycetophilidae and allied families). - Dipterists Digest 13: 29-35.

Chandler, P. J. 2005: Fauna Europaea: Mycetophilidae. In: de Jong, H. (ed.), Fauna Europaea: Diptera, Nematocera. Fauna Europaea, version 1.2. [www document] URL http://www.faunaeur.org (7 March 2005).

Dely-Draskovitš, A. 1974: Systematische und Ökologische Untersuchungen an den in Ungarn als Schädlinge der Hutpilze aufretenden Fliegen. 6. Mycetophilidae (Diptera). - Folia Entomol. Hung. 27: 29-41.

Edwards, F. W. 1925: British Fungus-Gnats (Diptera, Mycetophilidae) with a revised generic classification of the family. - Trans. Entomol. Soc. Lond. 73(1924): 505-670.

Eisfelder, I. 1955: Die häufigsten Pilzbewohner. - Zeitschrift fur Pilzkunde19: 12-20.

Hackman, W. 1980: A check list of the Finnish Diptera 1. Nematocera and Brachycera (s.str.). - Not. Entomol. $60: 17-48$.

Heikinheimo, O. \& Raatikainen, M. 1971: The recording of localities of biological finds in Finland. - Ann. Entomol. Fennici 37 (1a): 9-27.

Hippa, H., Jaschhof, M. \& Vilkamaa, P. 2004: Phylogeny of the Manotinae, with a review of Eumanota Edwards, Paramanota Tuomokoski and Promanota Tuomikoski (Diptera: Mycetophilidae). — Studia Dipterol. 11(2): 405-428.

Jakovlev, J. 2005: A new rearing method for revealing larval microhabitats of saproxylic Diptera. - In: Siitonen, J. (ed.), Saproxylic species in Fennoscandian forests - gathering ecological knowledge for applied 
use. 3rd Nordic Saproxylic Network meeting, Lammi Biol. Station, 7-9.12.2005.

Jakovlev, J., Kjærandsen, J. \& Polevoi, A. 2006: Seventy species of fungus gnats new to Finland (Diptera: Mycetophilidae). - Sahlbergia 11: 22-39.

Jaschhof, M. \& Hippa H. 2005: The genus Manota in Costa-Rica (Diptera, Mycetophilidae). — Zootaxa 1011:1-54

Khalidov, A. B. 1984: (Insects - destroyers of fungal fruiting bodies.) - Kazan State University. Kazan. 151 p. [In Russian].

Krivosheina, N. P., Zaitzev, A. I. \& Jakovlev, J. B. 1986: (Insects inhabiting fruiting bodies of macrofungi in the forest zone of the European part of USSR.) Nauka, Moscow. 309 pp. [In Russian].

Kurina, O., Polevoi, A., Götmark, F., Økland, B., Frank, N. \& Hedmark, K. 2004: Fungus gnats (Diptera: Sciaroidea excl. Sciaridae) in the Swedish boreonemoral forests. - Studia Dipterol. 11(2): 471-488.

Laštovka, P. 1988: Subfamily Mycetophilinae. Tribe Mycetophilini. - In: Soos, A. \& Papp, L. (eds.), Catalogue of Palaearctic Diptera. Vol. 3. CeratopogonidaeMycetophilidae: 263-280. Budapest, Akadémiai Kiadó.

Lundström, C. 1913: Neue oder wenig bekannte europäische Mycetophiliden. - Ann. Mus. Natl. Hung. 11: 305-322

Lundström, C. 1914: Beiträge zur Kenntnis der Dipteren Finlands. IX. Supplement 3. Mycetophilidae. - Acta Soc. F. Fl. Fenn. 39: 1-26.

Madwar, S. 1937: Biology and morphology of the immature stages of Mycetophilidae. - Phil. Trans. R. Soc. London. Ser. B 227: 1-110.

Polevoi, A.V. 2000: Fungus gnats (Diptera: Bolitophilidae, Ditomyiidae, Keroplatidae, Diadocidiidae, Mycetophilidae) in Karelia. - Karelian Research Centre,
Russian Academy of Sciences, Petrozavodsk. 84 pp. [In Russian].

Polevoi, A., Jakovlev, J. \& Zaitzev, A. 2006: Fungus gnats (Diptera: Bolitophilidae, Diadocidiidae, Keroplatidae and Mycetophilidae) new to Finland. - Entomol. Fennica 17: 161-169.

Ribeiro, E. 1990: Contribution to the study of Fungus gnats (Diptera, Mycetophiloidea) of Portugal. II. Seven new records. - Bol. Soc. Portug. Entomol. 118: 173-196.

Sedivy, J. \& Ševčík, J. 2003: Ichneumonoid (Hymenoptera: Ichneumonoidae) parasitoids of fungus gnats (Diptera: Mycetophilidae): rearing records from the Czech Republic. — Studia Dipterol. 10 (1): 153-158.

Ševčík, J. 2004: Diptera associated with fungi in the Poloniny National Park (Bukovskč vrchy Mts., Est. Slovakia). - Dipterol. Bohemoslovaca 11: 293-304.

Ševčík, J. 2005: New records of Sciophila Meigen from the Czech and Slovak Republics (Diptera:Mycetophilidae). - Časopis Slezského muzea Opava Série A 54:69-74.

Søli, G. E. E. 1997: The adult morphology of Mycetophilidae (s.str.), with a tentative phylogeny of the family (Diptera, Sciaroidea). - Entomol. Scand., Suppl. 50: $1-55$.

Zaitzev, A. I. 1990: (On the preimaginal stages of Manota unifurcata Lundst. and the systematic position of the subfamily Manotinae.) - Biologicheskie nauki 3: 6371 [In Russian].

Zaitzev, A. I. 2003: Fungus gnats (Diptera, Sciaroidea) of the fauna of Russia and adjacent regions. Part II. Int. J. Dipterol. Res. 14: 77-386.

Zaitzev, A. I., Jakovlev, J. \& Polevoi, A.V. 2005: Palaearctic species of the Boletina nitida group (Diptera: Mycetophilidae) including the description of a new species. - Studia Dipterol. 12 (2): 243-253. 